\title{
Antidiabetic Activity Studies of White Tea (Camellia sinensis (L.) O. Kuntze) Ethanolic Extracts in Streptozotocin-nicotinamide Induced Diabetic Rats
}

\author{
Lia Ardiana, Rani Sauriasari*, Berna Elya
}

\section{Lia Ardiana, Rani Sauriasari*, Berna Elya}

Faculty of Pharmacy, University of Indonesia, 16424, Depok, INDONESIA.

Correspondence

Rani Sauriasari

Faculty of Pharmacy, University of indonesia, 16424, Depok, INDONESIA.

Phone No: 62-21-78849002

Facsimile numbers: +62 21-78849001

E-mail: rani@farmasi.ui.ac.id

History

- Submission Date: 15-10-2017;

- Review completed: 09-11-2017.

- Accepted Date: 20-11-2017

DOI : 10.5530/pj.2018.1.31

Article Available online http://www.phcogj.com/v10/i1

\section{Copyright}

(C) 2018 Phcog.Net. This is an openaccess article distributed under the terms of the Creative Commons Attribution 4.0 International license.

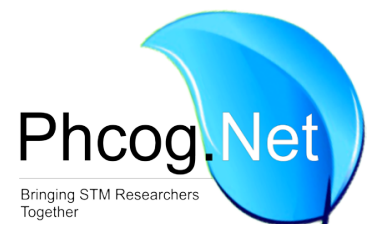

\begin{abstract}
Background: The high polyphenol content of white tea exhibits antiseptic and antioxidant properties that can prevent free radicals, inhibit oxidative stress and inflammation associated with various diseases such as obesity, diabetes and other degenerative diseases. Oral administration of white tea ethanolic extract (WTE) is expected to use as an alternative in the treatment of diabetes mellitus. Objective: This study aims to evaluate the effect of WTE on reducing fasting blood glucose levels in diabetic rats. Methods: Antidiabetic activity study of white tea extract performed on diabetic Sprague-Dawley male rats induced streptozotocinnicotinamide for 14 days of oral administration. The antidiabetic effect compared to normal control, diabetic control, and standard control groups. Results: The administration of WTE for 14 days showed decreased fasting blood glucose level in diabetic rats. The dose of $100 \mathrm{mg} / \mathrm{kg}$ BW of WTE has the highest effect on reducing fasting glucose level significantly compared to negative control group ( $p<0.05$ ). The content of flavonoids, especially catechin compounds are suspected to play a role in lowering fasting blood glucose levels. Conclusion: The administration of WTE for 14 days has potentially antidiabetic activity in diabetic rats induced streptozotocin-nicotinamide.
\end{abstract}

Key words: Antidiabetic, Camellia sinensis, Catechin, Hypoglycemic, Streptozotocin, White tea.

\section{INTRODUCTION}

Diabetes mellitus (DM) is a major public health problem, and its incidence has increased rates continuously. ${ }^{1}$ Insulin ineffectiveness in DM patients causes metabolic disorders characterized by high levels of blood glucose or hyperglycemia and accompanied by changes in lipid metabolism, carbohydrates, and proteins that may lead to an increased risk of complications from vascular disease. ${ }^{2}$ The global study report states that DM is one of the non-communicable diseases based on the number of cases and its prevalence has continued to increase over the last few decades. ${ }^{3,4,5}$

Research and development to get new drugs as an alternative medicine for DM have been mostly done mainly from herbal materials. One of popular herb in public is a tea leaf, Camellia sinensis (L.) O. Kuntze (family Theaceae). White tea is one type of tea taken is a very young shoot or tea leaves or buds that are known to have high polyphenol content and exhibits antiseptic and antioxidant properties. ${ }^{6}$ The process of white tea is quite simple that is through of steaming and drying to prevent the occurrence of the enzymatic oxidation process. ${ }^{7}$ The antioxidant properties of white tea can prevent free radicals, inhibit oxidative stress and inflammation associated with various diseases such as obesity, dyslipidemia, diabetes, cardiovascular, neurodegenerative and cancer. ${ }^{7}$ The recent studies related to the bioactive compound like polyphenolsflavonoids-catechins of tea due to their antioxidant activities which contribute to human health benefits. ${ }^{8}$ The recent research showed the in vitro inhibitory activity of WTE against the $\alpha$-amylase enzyme (with $99.11 \pm 0.01 \%$ inhibition percentage); $\alpha$-glucosidase $\left(\mathrm{IC}_{50} 10.54 \mu \mathrm{g} / \mathrm{mL}\right.$ ); and dipeptidyl peptidase IV (DPP-IV) enzyme (with $30.57 \pm 0.08 \%$ inhibition rate). ${ }^{9}$ This research considered that WTE has the highest inhibitory activity against DPP-IV enzyme. Therefore, to prove the in vivo antidiabetic activity of WTE, the study on the effect of reducing fasting blood glucose levels in diabetic animals will be carried out.

\section{MATERIALS AND METHODS}

Plant Material and Extraction

The white tea leaves (Camellia sinensis (L.) O. Kuntze) obtained from the Tea Plantation and Quinine Research Center in Gamboeng, West Java, Indo- 
nesia, was determined by Center for Plant Conservation Botanic Garden, Indonesian Institute of Science, Indonesia. The extraction process conducted by using reflux method with ethanol $70 \%$ as a solvent at $60{ }^{\circ} \mathrm{C}$ for $3 \mathrm{~h}$ and three times re-extraction. The filtrate from extraction process then evaporated using rotation evaporator.

\section{Chemicals}

Streptozotocin purchased from Sigma-Aldrich (Germany), and all other chemicals materials purchased from Merck (Germany) and Brataco Chemika (Indonesia).

\section{Animals}

Twelve-week-old male Sprague-Dawley rats weighing 300-350 g obtained from National Drug and Food Laboratory Center, at National Agency Drug and Food Control (NADFC), Indonesia. The animals used in this study have received approval from the Medical Research Ethics Commission of the Faculty of Medicine, University of Indonesia. All animals housed in an air-conditioned room and supplied with standard pellet food and drinking water ad libitum. All rats were divided into six groups of four animals each and acclimatized for seven days before the antidiabetic studies conducted.

\section{Induction of Diabetes}

Diabetic induction prepared by intraperitoneal injection of $55 \mathrm{mg} / \mathrm{kg}$ of STZ (dissolved in $0.05 \mathrm{M}$ citrate buffer solution, $\mathrm{pH}$ 4.5) $20 \mathrm{~min}$ after intraperitoneal administration of $100 \mathrm{mg} / \mathrm{kg}$ nicotinamide (dissolved in normal saline solution) in overnight fasting rats. ${ }^{10,11}$ About $1 \mathrm{~h}$ after STZ-nicotinamide induction, the animals were given $5 \%$ glucose solution orally for $12 \mathrm{~h}$ to prevent hypoglycemia and fasting blood glucose was measured $48 \mathrm{~h}$ after the induction. The rats with fasting blood glucose levels greater than $150 \mathrm{mg} / \mathrm{dL}$ considered as diabetic animals. ${ }^{12}$

\section{Experimental design}

The animals divided into six groups of four rats of each, consisting of three control groups and three treatment groups. Group I as standard control, healthy rats administered with daily oral of $0.5 \%$ carboxymethylcellulose (CMC). Group II as the negative control, diabetic rats administered with daily oral of $0.5 \%$ CMC. Group III as the positive control, diabetic rats administered with daily oral of $90 \mathrm{mg} / \mathrm{kg}$ sitagliptin. Group IV as lowest dose, diabetic rats administered with daily oral of $50 \mathrm{mg} / \mathrm{kg}$ white tea ethanolic extract (WTE). Group V as middle dose, diabetic rats administered with daily oral of $100 \mathrm{mg} / \mathrm{kg}$ WTE. Group VI as highest dose, diabetic rats administered with daily oral of $200 \mathrm{mg} / \mathrm{kg}$ WTE.

The materials test administered at two days after induction of diabetic by injection of STZ for 14 days. Initial fasting blood glucose levels deter- mined and after the induction fasting blood glucose were determined on the first day (D1) before the administration of the extracts and the 14th day (D14) after. Fasting blood glucose levels were determined by collecting the blood from the tail of the rats and measured using glucometer (Accu-Check ${ }^{\oplus}$ Active). Body weight of all animals was measured once before the treatment and twice after the treatment, on the 7th day (D7) and the 14th-day end of studies (D14).

\section{Statistical Analysis}

Statistical analysis determined as mean value \pm standard error (SE). The data with normal distribution analyzed with one-way ANOVA followed by multiple comparisons using Tukey test. However, abnormal distribution analyzed with Kruskal-Wallis test. Probability level of less than 5\% $(\mathrm{p}<0.05)$ was considered significant.

\section{RESULTS}

\section{Hypoglycaemic effect}

Table 1 shows the fasting blood glucose levels in control and treatment groups. The fasting blood glucose levels significantly increase greater than $200 \mathrm{mg} / \mathrm{dl}$ compared to the normal group, $48 \mathrm{~h}$ after induction of STZ. Administration of WTE for 14 days in diabetic rats showed a decrease in fasting blood glucose levels in diabetic rats. White tea extract at the middle dose $100 \mathrm{mg} / \mathrm{kg}$ BW shows highest reducing fasting blood glucose effect $(101 \pm 8.33 \mathrm{mg} / \mathrm{dl})$ than at lower dose $50 \mathrm{mg} / \mathrm{kg}$ BW $(195.67 \pm 16.22 \mathrm{mg} / \mathrm{dl})$ and maximum dose $200 \mathrm{mg} / \mathrm{kg} \mathrm{BW}(149 \pm 52.21$ $\mathrm{mg} / \mathrm{dl}$ ). The fasting blood glucose levels of all treatment groups at the end of studies showed a significant difference between the negative control group, $(\mathrm{P}<0.05)$.

\section{Body weight effect}

The record of body weight during the studies represented in Table 2. The increase in body weight in the treatment group was shown by the group of $100 \mathrm{mg} / \mathrm{kg}$ BW WTE although the increase was not significant when compared with the initial burden. The development of body weight in the group of $50 \mathrm{mg} / \mathrm{kg} \mathrm{BW}$ WTE tended to be stable even though on the 7th day also decreased, whereas body weight loss also occurred in the group of $200 \mathrm{mg} / \mathrm{kg}$ BW WTE although not significant compared before treatment.

\section{DISCUSSION}

The present study was conducted to evaluate the effect of WTE on reducing fasting blood glucose levels in diabetic rats. The result of this studies shows that consumption of WTE for 14 days reduced fasting blood glucose levels in streptozotocin-induced diabetic rats. However, this data

Table 1: Effect of white tea extract on fasting blood glucose of diabetic rats.

\begin{tabular}{cccc}
\hline \multirow{2}{*}{ Group Dose (mg/kg BW) } & \multicolumn{3}{c}{ Fasting Blood Glucose (mg/dL) } \\
\cline { 2 - 4 } & Initial & D1 & D14 \\
\hline Normal (CMC 0.5\%) & $83.67 \pm 2.60$ & $87.33 \pm 4.09$ & $84.67 \pm 1.33^{* *}$ \\
Negative control (CMC 0.5\%) & $79.00 \pm 2.64$ & $251.67 \pm 11.55^{*}$ & $335.67 \pm 12.44$ \\
Positive control (Sitagliptin 90) & $74.67 \pm 3.18$ & $296.33 \pm 17.49^{*}$ & $68.67 \pm 3.18^{* *}$ \\
WTE 50 & $90.33 \pm 8.37$ & $294.4 \pm 44.14^{*}$ & $195.67 \pm 16.22^{* *}$ \\
WTE 100 & $87.67 \pm 10.20$ & $234.67 \pm 40.77^{*}$ & $101 \pm 8.33^{* *}$ \\
WTE 200 & $72.00 \pm 0.57$ & $219.33 \pm 38.96^{*}$ & $149 \pm 52.21^{* *}$ \\
\hline
\end{tabular}

The data represent the mean $\pm \mathrm{SE}(\mathrm{n}=4)$; *Significantly different as compared to the normal group, $\mathrm{p}<0.05$; **Significantly different as compared to negative control, $\mathrm{p}<0.05$; BW-body weight; WTEwhite tea ethanolic extract. 
Table 2: Effect of white tea extract on body weight changes in diabetic rats.

\begin{tabular}{ccccc}
\hline \multirow{2}{*}{ Group Dose (mg/kg BW) } & \multicolumn{4}{c}{ Body Weight (g) } \\
\cline { 2 - 5 } & Initial & D7 & D14 & $\Delta$ BW \\
\hline Normal (CMC 0.5\%) & $327.00 \pm 8.02$ & $317.33 \pm 9.68$ & $319.33 \pm 6.23$ & $7.67 \pm 2.33$ \\
Negative control (CMC 0.5\%) & $308.67 \pm 3.18$ & $279.67 \pm 8.51$ & $270.33 \pm 19.34$ & $38.33 \pm 21.85$ \\
Positive control (Sitagliptin 90) & $306.67 \pm 13.86$ & $297.67 \pm 14.19$ & $294.00 \pm 20.65$ & $12.67 \pm 7.22$ \\
WTE 50 & $327.33 \pm 9.21$ & $296.67 \pm 19.38$ & $327.00 \pm 23.03$ & $0.33 \pm 13.86$ \\
WTE 100 & $288.67 \pm 4.67$ & $288.33 \pm 1.76$ & $296.67 \pm 9.34$ & $-8.00 \pm 5.13$ \\
WTE 200 & $312.00 \pm 16.2$ & $294.00 \pm 20.79$ & $293.00 \pm 24.43$ & $19.00 \pm 9.02$ \\
\hline
\end{tabular}

The data represent the mean \pm SE $(n=4)$; BW-body weight; FTE-white tea ethanolic extract.

did not show any correlation between dose and response. The highest decrease in fasting blood levels reaches at the dose of $100 \mathrm{mg} / \mathrm{kg} \mathrm{BW}$ which statistically significantly different compared to negative control group, $(\mathrm{p}<0.05)$.

Several studies in green tea extract have reported that this chemicalinduced hyperglycemia can ameliorate by feeding green tea or its polyphenols, flavonoids, and catechins. ${ }^{13}$ Therefore, the hypoglycemic activity of WTE in this studies possibly related to the content of bioactive compounds such as polyphenols in tea leaves that play a role in providing health benefits to humans. ${ }^{9}$ Tea flavonoids are antioxidants that can protect the damage of pancreatic cells from free radicals. The content of alkaloids and tannins (epigallocatechin) also play a role in lowering blood glucose levels possible through inhibition of glucose absorption in the intestine. This condition support by other studies suggesting that epigallocatechin-3-gallate (EGCG) has a role in reducing blood glucose levels by inhibiting the absorption of intestinal glucose by glucose transporter and decreasing the expression of genes that control gluconeogenesis. ${ }^{14}$

Increased insulin-stimulated by glucose uptake, inhibition of intestinal glucose transporters and decreased gene expression that control gluconeogenesis is a mechanism that contributes to the antihyperglycemic effect of tea leaf extract. ${ }^{11}$ The other in vivo studies on green tea reported that insulin-like effects of polyphenols play a role in lowering blood glucose, but they also increase insulin sensitivity and reduce oxidative stress in experimental animals. ${ }^{14}$ Based on the above there is a direct relationship between antioxidant activity and hypoglycemic produced by white tea leaves. However, the studies with a treatment time longer than 14 days is required to ensure the antidiabetic effect of white tea extracts and confirm this mechanism.

Based on the data of body weight changes, Table 2, the STZ induction diabetic shows a tendency of body weight decrease in all groups of diabetic rats, and it is seeing up a 7th day after the treatment. Body weight loss in diabetic animal associated with dehydration and catabolism of fats and proteins due to proteolysis on muscular tissues occurred in insulin deficiency conditions. ${ }^{11,15}$ At the end of the study, the body weight of the diabetic rat's group tended to increase but did not occur in diabetic rats of the negative control group that managed to continue to decline. The body weight of the normal group also decreased at the end of treatment but was not significant when compared with the initial weight before treatment. However, based on statistical test results in each control groups and treatment groups, there was no significant difference in body weight changes at the end of treatment compared with before treatment, $(\mathrm{P}>0.05)$.

\section{CONCLUSION}

In conclusion, the study showed that white tea leaf ethanolic extract has a potential effect on reducing fasting blood glucose levels in diabetic rats induced by streptozotocin-nicotinamide compared with the negative control group. The highest decrease fasting glucose level showed at doses of $100 \mathrm{mg} / \mathrm{kg}$ BW white tea extract. However, the studies with a treatment time longer than 14 days is required to ensure the antidiabetic effect of white tea extracts and confirm this mechanism.

\section{ACKNOWLEDGEMENT}

This study supported by PITTA Grant University of Indonesia. The authors thank all their colleagues for their great prestigious encouragement in accomplishing this task.

\section{CONFLICT OF INTEREST}

The authors have no conflict of interest to declare.

\section{ABBREVIATIONS}

WTE: White tea ethanolic extract, BW: Body Weight; DM: Diabetes mellitus; IC : $_{50}$ Inhibition concentration; DPP-IV: Dipeptidyl_peptidase IV; STZ: Streptozotocin, CMC: Carboxy methyl cellulose, SE: Standard error, EGCG: epigallocatechin-3-gallate.

\section{REFERENCES}

1. Azeez A, Tomy S, Ali-Abdalla FM, Suresh R, Johnson B. Antidiabetic effect of Polyherbal Formulation "Kathakakhadiradi Kashyam" in Streptozotocin induced Diabetic rats. J Young Pharm. 2016;8(4):496-9.

2. World Health Organization. Definition and Diagnosis of Diabetes Mellitus and Intermediate Hyperglycemia. Report of a WHO/IDF Consultation. Geneve; 2006

3. Beaglehole R, Yach D. Globalisation and the prevention and control of noncommunicable disease: The neglected chronic diseases of adults. Lancet. 2003;362(9387):903-8.

4. International Diabetes Federation. IDF Diabetes Atlas. Seventh Edition. 2015

5. World Health Organization. Global Report on Diabetes. WHO Library Cataloguing in Publication Data. Geneve. 2016;978.

6. Thring TS, Hili P, Naughton DP. Antioxidant and potential anti-inflammatory activity of extracts and formulations of white tea, rose, and witch hazel on primary human dermal fibroblast cells. J Inflammation (Lond). 2011;8(1):27.

7. Dias TR, Tomás G, Teixeira NF, Alves MG, Oliveira PF, Silva BM. White Tea (Camellia sinensis (L.): Antioxidant Properties and Beneficial Health Effects. Inter J Food Sci Nutr Diet. 2013;2(2):19-26.

8. Goenka P, Sarawgi A, Karun V, Nigam AG, Dutta S, Marwah N. Camellia sinensis (Tea): Implications and role in preventing dental decay. Pharmacognosy Rev. 2013;7(14):3-8.

9. Elya B, Handayani R, Sauriasari R, Azizahwati, Hasyyati US, Permana IT, et al. Antidiabetic activity and phytochemical screening of extracts from Indonesian plants by inhibition of alpha amylase, alpha glucosidase and dipeptidyl peptidase IV. Pakistan J Biological Sci. 2015;18(6):273-8.

10. Chandran R, Primelazhagan T, Shanmugam S, Thankarajan S. Antidiabetic activity of Syzygium calophyllifolium in Streptozotocin-Nicotinamide induced Type-2 diabetic rats. Biomed Pharmacotherapy. 2016;82:547-54

11. Sundaram R, Naresh R, Shanthi P, Sachdanandam P. Modulatory effect of green tea extract on hepatic key enzymes of glucose metabolism in streptozotocin and high fat diet induced diabetic rats. Phytomedicine. 2013;20(7):577-84. 
12. King AJF. The use of animal models in diabetes research. Br J Pharmacology 2012;166(3):877-94.

13. Islam S. Phytomedicine Effects of the aqueous extract of white tea (Camellia sinensis) in a streptozotocin-induced diabetes model of rats. Euro J Integrative Med. 2011:19(1):25-31.
14. Salim KS. Hypoglycemic Property of Ginger and Green Tea and their Possible Mechanisms in Diabetes Mellitus. Open Confer Proceeding J. 2014;5:13-9

15. Jangir RN, Jain GC. Evaluation of antidiabetic activity of hydro alcoholic extract of Cassia fistula Linn. pod in streptozotocin-induced diabetic rats. Pharmacognosy J. 2017:9(5):599-606.

\section{GRAPHICAL ABSTRACT}

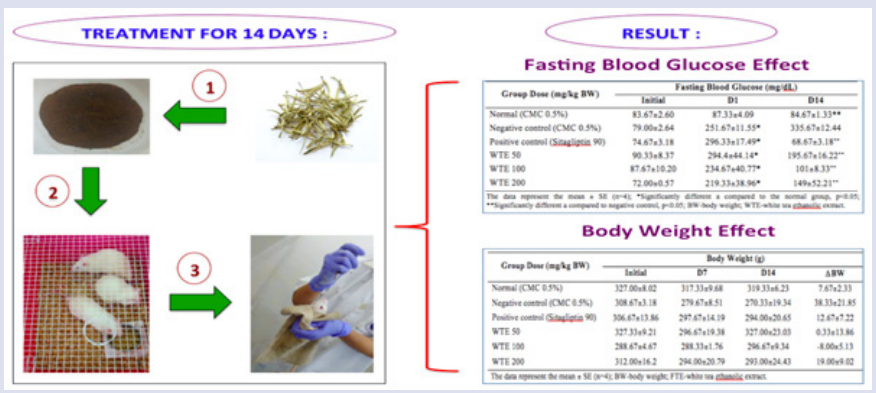

\section{SUMMARY}

- Administration of WTE at dose $100 \mathrm{mg} / \mathrm{kg} \mathrm{BW}$ for 14 days in diabetic rats showed a decrease in fasting blood glucose levels in diabetic rats.

- The fasting blood glucose levels of all treatment groups at the end of studies showed a significant difference between the negative control group, $(P<0.05)$.

- The body weight of the diabetic rat's group shows a tendency of body weight decrease, although it is no significant difference in body weight changes at the end compared with before treatment.

\section{ABOUT AUTHORS}

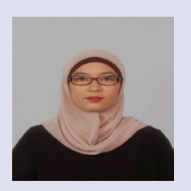

Lia Ardiana: is a researcher at the Faculty of Pharmacy, University of Indonesia. She graduated in Bachelor of Pharmacy from Bandung Institute of Technology and Magister degree from Faculty of Pharmacy, University of Indonesia. Her magister research focused on the evaluation of toxicity and antidiabetic activity of Indonesian herbal medicines.

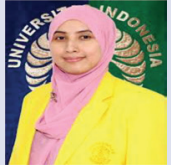

Rani Sauriasari: working as lecturer and researcher in Faculty of Pharmacy, University of Indonesia. Her doctoral degree obtained from Public Health (Medical Faculty), Okayama University, Japan. Currently, she is positioned as Manager of Research and Community Engagement, Faculty of Pharmacy, University of Indonesia. Has to experience in the area of Biochemistry, Analytical Chemistry, and Pharmacology, working mainly in medicinal plants and new research drugs.

Berna Elya: is a Professor and researcher with the mainly area in isolation of new compound from medicinal plants, pharmacognosy and phytochemistry. Currently, she is positioned as lecturer and Head of Laboratory of Pharmacognosy, Faculty of Pharmacy, University of Indonesia.

Cite this article: Ardiana L, Sauriasari R, Elya B. Antidiabetic Activity Studies of White Tea (Camellia sinensis (L.) O. Kuntze) Ethanolic Extracts in Streptozotocin-nicotinamide Induced Diabetic Rats. Pharmacog J. 2018;10(1):186-9. 